\title{
Chemotherapy with gemcitabine, paclitaxel, and cisplatin in the treatment of patients with advanced transitional cell carcinoma of the urothelium
}

\author{
THORSTEN H. ECKE ${ }^{1}$, PETER BARTEL ${ }^{1}$, STEFAN KOCH $^{2}$, JÜRGEN RUTTLOFF $^{1}$ and FRANZ THEISSIG ${ }^{2}$ \\ ${ }^{1}$ Department of Urology; ${ }^{2}$ Institute of Pathology, Helios Hospital, Bad Saarow, Germany
}

Received June 23, 2006; Accepted August 11, 2006

\begin{abstract}
Chemotherapeutic agents are active in advanced bladder cancer, and various combinations have shown promising results. The objective of this study was to evaluate the efficacy of combination chemotherapy with gemcitabine, paclitaxel, and cisplatin in patients with advanced urothelial carcinoma. Fifty-nine patients with metastatic or locally advanced transitional cell carcinoma of the urothelium were treated between 2000 and 2005. No patient had received any previous systemic chemotherapy. All patients received chemotherapy intravenously with gemcitabine at a dose of $1000 \mathrm{mg} / \mathrm{m}^{2}$ on days 1 and 8 , paclitaxel at a dose of $80 \mathrm{mg} / \mathrm{m}^{2}$ on days 1 and 8 , and cisplatin at a dose of $50 \mathrm{mg} / \mathrm{m}^{2}$ on day 2 . Treatment courses were repeated every 21 days. After completion of four to six courses in this regimen an intravenous application of gemcitabine was repeated every 28 days at a dose of $1000 \mathrm{mg} / \mathrm{m}^{2}$. Fifty-nine patients were treated between 2000 and 2005 . Nine patients $(15 \%)$ had $\geq 1$ visceral site of metastases, and no patient had received any previous systemic chemotherapy. Forty-eight patients (81\%) achieved objective responses to treatment ( $56 \%$ complete responses). The median actuarial survival was 22 months, and the actuarial 1 -year and 2-year survival rates were $68 \%$ and $39 \%$, respectively. After a median follow-up of 17.5 months, 29 patients remained alive and 25 were free of disease progression. The median progression-free survival for the entire group was 10 months. The median survival time for patients with an Eastern Cooperative Oncology Group (ECOG) status of 0,1 , and 2 was $37.5,17$, and 12 months, respectively. Grade 3-4 neutropenia occurred in 39\% of the patients. The combination of gemcitabine, paclitaxel, and cisplatin is a highly effective and tolerable regimen for patients with advanced urothelial carcinoma. This treatment should
\end{abstract}

Correspondence to: Dr Thorsten H. Ecke, Department of Urology, Helios Hospital, Pieskower Strasse 33, D-15526 Bad Saarow, Germany

E-mail: tho_ecke@hotmail.com

Key words: cisplatin, chemotherapy, gemcitabine, paclitaxel, urothelial cell cancer be considered as a suitable option that deserves further prospective evaluation. The ECOG performance status is an important predictive factor for survival.

\section{Introduction}

Transitional cell carcinoma (TCC) of the urothelium has a high prevalence among the elderly. Approximately $80 \%$ of those who are affected are between 50-79 years of age (1). When diagnosed, 20-30\% of bladder carcinomas display muscle infiltration, and $50 \%$ of these metastasize (2-4). The prognosis for metastasized urothelial carcinomas is poor and the average survival rate for untreated patients is 3-6 months (5).

Advanced transitional cell carcinoma of the urothelium is moderately sensitive to chemotherapy, and there are a number of agents that produce response rates in the 10-40\% range (6-8). Cisplatin is one of the most effective singleagent treatments for metastatic urothelial cancer, and forms the cornerstone of combination chemotherapy.

In the 1980s the chemosensitivity of urothelial cell cancer was recognized when phase II studies demonstrated the activity of cisplatin, methotrexate, adriamycin, vinblastine and 5FU in advanced and/or metastatic disease. The next step in developing a more effective therapy was to combine these known effective agents into two-, three-, and four-drug combinations (9). In 1985 investigators from the Memorial Sloan Kettering Cancer Center reported a four-drug regimen of cisplatin, doxorubicin, methotrexate and vinblastine (MVAC) (10). The initial study on 24 patients gave an overall response rate of $71 \%$. In an updated report on a larger series of 121 evaluable patients, the overall response rate to MVAC was $72 \%$, with a clinical complete response rate to chemotherapy alone of $18 \%$ and with an additional $11 \%$ of the patients being rendered disease free with post chemotherapy surgery (11). Unfortunately, MVAC therapy is associated with significant morbidity. Also the prognosis of patients with metastatic transitional cell carcinoma remains poor, with a median survival of only 12-14 months (6,11-13). Furthermore, the MVAC regimen is relatively toxic, and it is difficult to administer to elderly patients and to patients who have a poor performance status.

In the past decade, several new chemotherapeutic agents have shown activity against advanced urothelial bladder 
cancer, including the taxanes paclitaxel and docetaxel (14-18), and gemcitabine (19-22). Gemcitabine (Gemzar ${ }^{\circledR}$; Eli Lilly \& Co., Indianapolis, IN, USA) is a pyramidine antimetabolite that has preclinical and clinical activity against urothelial cancer with an overall response rate of $30 \%$ in previously treated and untreated patients $(19,23)$. Gemcitabine offers proven activity against a range of solid tumors $(20,24-26)$. In particular, in metastatic urothelial cancer, gemcitabine alone yielded response rates of $23-29 \%$ with a complete response rate of $4-13 \%$, in both previously treated and untreated patients (5). The good activity and toxicity profile of single-agent gemcitabine and its synergism with cisplatin in pre-clincal models (27) have led to the development of this combination in advanced TCC. Von der Maase et al (13) reported on a large multinational phase III trial comparing the M-VAC regimen with gemcitabine plus cisplatin (GC), with a total of 405 patients accrued. The final results showed that the two regimens were similar in terms of response rate, time to progression and survival. However, the GC combination provided a better safety profile with decreased toxicity. Based on these data, the GC combination proved to be a standard alternative treatment in patients with advanced TCC.

Paclitaxel $\left(\right.$ Taxol $^{\circledR}$ ) is an anti-microtubule agent that stabilizes microtubules, induces $\mathrm{G} 2 / \mathrm{M}$ cell cycle arrest, as well as the phosphorylation of the anti-apoptotic protein bcl-2 (28), and has preclinical and clinical activity against TCC $(16,29)$. Initial phase II studies of two-drug combinations of docetaxel, or paclitaxel, with cisplatin, have shown activity in untreated patients, with response rates that are in the same range as obtained with MVAC (30-35).

In view of the activity of gemcitabine and the taxanes, the partially non-overlapping toxicities of these agents and their different mechanisms of action, the next logical step was to combine these compounds, and incorporate platinum as the back-bone in a three-drug regimen. Investigators in Spain conducted phase I/II trials of the triplet combination of paclitaxel, cisplatin, and gemcitabine (PCG) in a total of 61 patients (36). The investigators began their study in a formal phase I setting, escalating the dose levels of both paclitaxel and gemcitabine, administered weekly, on days 1 and 8 , with a fixed dose of $70 \mathrm{mg} / \mathrm{m}^{2}$ cisplatin, on day 1 , every three weeks. At dose level 4, with paclitaxel at $90 \mathrm{mg} / \mathrm{m}^{2}$ weekly, grade 3 asthenia was determined to be the dose-limiting toxicity. With this schedule and dose intensity, asthenia, as well as myelotoxicity were manageable. G-CSF was used only for secondary prophylaxis in patients in whom either neutropenic fever or grade 4 neutropenia had been observed in the preceding cycle. The phase I study (15 patients) and phase II study (46 evaluable patients) together gave an overall response rate of $78 \%$ and a median survival time for the phase I and the phase II part of the study of 24 and 16 months, respectively. In view of these results, several international groups of oncology have begun the largest randomized trial ever designed in metastatic bladder cancer to compare the threedrug design regimen of PCG with the two-drug combination of GC. A total of 610 patients will be needed to detect a difference in survival of 4 months (from 14 to 18 months). The study is restricted to patients with a good clinical performance status [an Eastern Cooperative Oncology Group (ECOG) status of 0 or 1] and a creatinine clearance of at least $60 \mathrm{ml} / \mathrm{min}$.
Since information about the predictive factors for response and survival is needed for the selection of patients who are likely to benefit from new combinations and for stratification purposes in randomized trials, an analysis of the predictive factors for response and survival with the regimen containing PCG was performed (37). The pretreatment characteristics analyzed were age, gender, ECOG performance status (38), histopathology, visceral metastasis (bone, liver, lung), number of sites of disease, LDH and hemoglobin. The factors that were associated with decreased survival in the univariate analysis were a performance status of $>0$, the presence of visceral metastasis, and more than one site of malignant disease.

In our study we also included patients with an ECOG status of 2 and a lower creatinine clearance with the application of a reduced dose. This nonrandomized retrospective study was designed to evaluate the feasibility, toxicity, and efficacy of this three-drug chemotherapy regimen in patients with advanced urothelial carcinoma. Previous experience with either gemcitabine plus platinum regimens had produced response rates of $41-56 \%$, with median survivals in the range of 10-14 months. Therefore, the achievement of a response rate of $>60 \%$ or a median survival of $>14$ months with this regimen would be indicative of sufficient activity to proceed with further development (39).

\section{Patients and methods}

Eligibility. Patients who were eligible for this trial were required to have histologically confirmed transitional cell carcinoma of the urothelial tract (bladder, ureter, or renal pelvis) that was either metastatic or locally advanced and unresectable. Patients with locally advanced, unresectable bladder carcinoma who had any possibility of curative therapy with combined-modality treatment were excluded from this trial. All patients were required to have measurable disease. Patients were not allowed to have received a previous systemic chemotherapy regimen. Previous intravesical treatment was allowed if the most recent intravesical therapy was completed $>1$ month prior to the study enrolment. Previous radiation therapy was not allowed.

Additional eligibility requirements included the following: An ECOG performance status of 0 to 2, a leukocyte count of $\geq 3,000 / \mu 1$, a platelet count of $\geq 100,000 / \mu 1$, serum bilirubin $<1.5 \mathrm{mg} / \mathrm{dl}$, serum creatinine $\geq 2.5 \mathrm{mg} / \mathrm{dl}$, and age $>18$ years. Patients with other active malignancies or with any other serious or active medical conditions were excluded. Pregnant or lactating females were ineligible. All patients were required to provide written informed consent prior to the study enrolment.

Pretreatment evaluation. Prior to enrolling in this trial, all patients were required to have a complete history, physical examination, complete blood counts, differential, chemistry profile, and urinalysis. In addition, patients underwent computed tomography scans of the chest, abdomen, and pelvis with appropriate tumor measurements.

Treatment. All patients received treatment with the following regimen: Gemcitabine at a dose of $1,000 \mathrm{mg} / \mathrm{m}^{2}$ as a $30-\mathrm{min}$ 
intravenous infusion followed by paclitaxel at a dose of $80 \mathrm{mg} / \mathrm{m}^{2}$ as a 1 -h intravenous infusion on days 1 and 8 . On day 2 cisplatin was applied at a dose of $50 \mathrm{mg} / \mathrm{m}^{2}$ as an intravenous infusion and hydration with $2,000 \mathrm{ml} \mathrm{NaCl} 0.9 \%$. The regimen was repeated every 21 days. Patients received standard paclitaxel premedication and antiemetic prophylaxis.

After completion of four to six courses in this regimen a further therapy followed: Gemcitabine at a dose of $1,000 \mathrm{mg} / \mathrm{m}^{2}$ as a 30-min intravenous infusion. The regimen was repeated every 28 days.

For the patients who had rapid progress after completing the three-drug regimen with gemcitabine, paclitaxel, and cisplatin or during gemcitabine monotherapy, we used the common three-drug chemotherapy with methotrexate, epirubicine, and cisplatin. The regimen of the courses was as follows: Methotrexate at a dose of $30 \mathrm{mg} / \mathrm{m}^{2}$ as a very short intravenous infusion on days 1 and 15 . On day 2 cisplatin was applied at a dose of $70 \mathrm{mg} / \mathrm{m}^{2}$ as an intravenous infusion and hydration with $2,000 \mathrm{ml} \mathrm{NaCl} 0.9 \%$ followed by epirubicine at a dose of $30 \mathrm{mg} / \mathrm{m}^{2}$ as a short intravenous infusion. The regimen was repeated every 21 days. Patients received standard premedication and anti-emetic prophylaxis.

Dose modifications. All patients received full doses of all 3 agents on day 1 of the first course of treatment. Subsequent doses were based on the hematological and nonhematological toxicity observed. Dose modifications for myelosuppression were determined by the blood counts measured on the day of scheduled treatment. Nadir blood counts were not used as a basis for dose reduction.

On day 1 of each course, full doses of all drugs were administered if the leukocyte count was $\geq 3,000 / \mu 1$ and the platelet count was $>100,000 / \mu 1$. If the leukocyte count was $<3,000 / \mu 1$ or the platelet count was $<100,000 / \mu 1$, then treatment was delayed for one or two days.

All patients with an ECOG performance status of 2, or with renal insufficiency in the stage of compensated retention received reduced doses of $50 \%$ to $70 \%$. In the case of good tolerance of the therapy we applied higher doses for the following cycles.

Assessment of treatment efficacy. Patients were evaluated for response to treatment after the completion of 4 courses (12 weeks). Re-evaluation included a repeat of all previously abnormal radiological studies with a repeat of objective tumor measurement. Patients who achieved an objective response (complete or partial) or stable disease after the completion of four courses of therapy continued treatment with this regimen. Re-evaluations were performed after the completion of each additional courses of therapy. Treatment was continued for a total of six courses. Patients who completed 6 courses and remained in remission were given further treatment with a single dose of gemcitabine. This additional treatment was continued for at least two years. Patients who completed these two years of gemcitabine monotherapy and remained in remission did not receive any further specific treatment and were re-evaluated for ongoing response at 3-month intervals including a clinical examination, ultrasound of the abdomen and computed tomography scans of the chest, abdomen, and pelvis with appropriate tumor measurements.
Table I. Histological staging and grading of patients.

\begin{tabular}{lcrrr}
\hline $\begin{array}{l}\text { Staging/ } \\
\text { grading }\end{array}$ & G1 & G2 & G3 & Total \\
\hline T1 & 1 & 1 & 2 & 4 \\
T2 & 1 & 3 & 11 & 15 \\
T3-4 & 0 & 6 & 26 & 32 \\
T4 & 0 & 0 & 8 & 8 \\
Total & 2 & 10 & 47 & 59 \\
\hline
\end{tabular}

Response definitions. Responses were defined using the World Health Organization Response criteria. A complete response required the total disappearance of all clinically and radiographically detected tumors for at least 4 weeks. Patients had partial response if treatment produced a reduction of $\geq 50 \%$ in the size of measurable lesions, as measured by the product of the greatest perpendicular dimensions, with no evidence of new disease if measurable lesions were reduced by $<50 \%$ or increased by $<25 \%$, as determined by the measurement of the products of the greatest perpendicular dimensions, with no new lesions appearing. Patients who had any appearance of new lesions or who had an increase of $>25 \%$ in the size of any existing lesions had progressive disease.

Progression-free survival was defined as the interval between the date of the first treatment and the date of documented tumor progression.

Statistical analysis. Survival was measured from the time of the initiation of chemotherapy until death or the last follow-up. Actuarial survival curves were constructed using the KaplanMeier method (40). Statistical analysis included the Chisquare test after Pearson's correlation was computed and performed by the computer program SPSS 12.0.1. All patients who received at least two doses of treatment were included in the toxicity analysis. Toxicity was evaluated using the National Cancer Institute Common Toxicity Criteria.

\section{Results}

Patient population. From August 2000 to November 2005 a total of 59 patients were included in the trial. Forty-five male patients and 14 female patients (average age 69.7 years, median age 70 years) were included. The pathohistological stage and grade is shown in Table I. The patient characteristics are summarized in Table II. The majority of patients (35 out of 59 patients $=59 \%$ ) had metastatic disease. Four patients $(7 \%)$ were treated with radical tumor surgery and came to progress (lymph node or visceral metastases) $>1$ year after the first treatment. Twenty-seven patients (46\%) had lymph node or visceral metastases just after radical tumor surgery. Six $(10 \%)$ patients had lymph node or visceral metastases before surgery and no surgical treatment was done before chemotherapy. Nineteen patients $(32 \%)$ had neither lymph node nor visceral metastases just after radical tumor surgery. Three $(5 \%)$ patients had neither lymph node nor visceral 
Table II. Patient characteristics ( $\mathrm{n}=59$ patients $)$.

\begin{tabular}{lc}
\hline Characteristic & No. of patients $(\%)$ \\
\hline Age (years) & 70 \\
Median & $52-82$ \\
Range & \\
Gender & $45(76)$ \\
Male & $14(24)$ \\
Female & \\
TNM stage & $24(41)$ \\
Any T, N0, M0 & $26(44)$ \\
Any T, N+, M0 & $9(15)$ \\
Any T, any N, M1 & \\
ECOG performance status & $24(41)$ \\
0 & $26(44)$ \\
1 & $9(15)$ \\
2 & \\
Previous treatment & \\
Radical tumor surgery & \\
Site of tumor & \\
Locoregional/lymph node only (pN1) & \\
pN2 only & \\
Visceral metastases & \\
\hline
\end{tabular}

metastases before surgery and no surgical treatment was done before chemotherapy because of non-compliance for surgical therapy. In summary, we included 24 patients (41\%) with advanced urothelial cancer without lymph node or visceral metastases, 26 patients (44\%) had advanced urothelial cancer and lymph node metastases without visceral metastases, and 9 patients $(15 \%)$ had advanced urothelial cancer and visceral metastases (Table II). The ECOG performance status at the point of starting chemotherapy was 0 for 24 patients (41\%), 1 for 26 patients $(44 \%)$, and 2 for 9 patients $(15 \%)$. Before the beginning of chemotherapy 48 patients $(81 \%)$ had radical tumor surgery: Radical cystectomy or nephroureterectomy. No patient had received previous chemotherapy or radiation.

Treatment schedule. All 59 patients received at least two courses of treatment and were evaluated for response. Thirtyfour patients received gemcitabine monotherapy. Five patients received the second line chemotherapy (MEC) because of rapid progression after the three-drug regimen with gemcitabine, paclitaxel, and cisplatin or during gemcitabine monotherapy.

The median number of treatment courses received in the first line three-drug regimen with gemcitabine, paclitaxel, and cisplatin was five (range, two to seven courses). A reduced dose of the three drugs was administered to 38 patients $(64 \%)$. This high number of reduced doses given is because

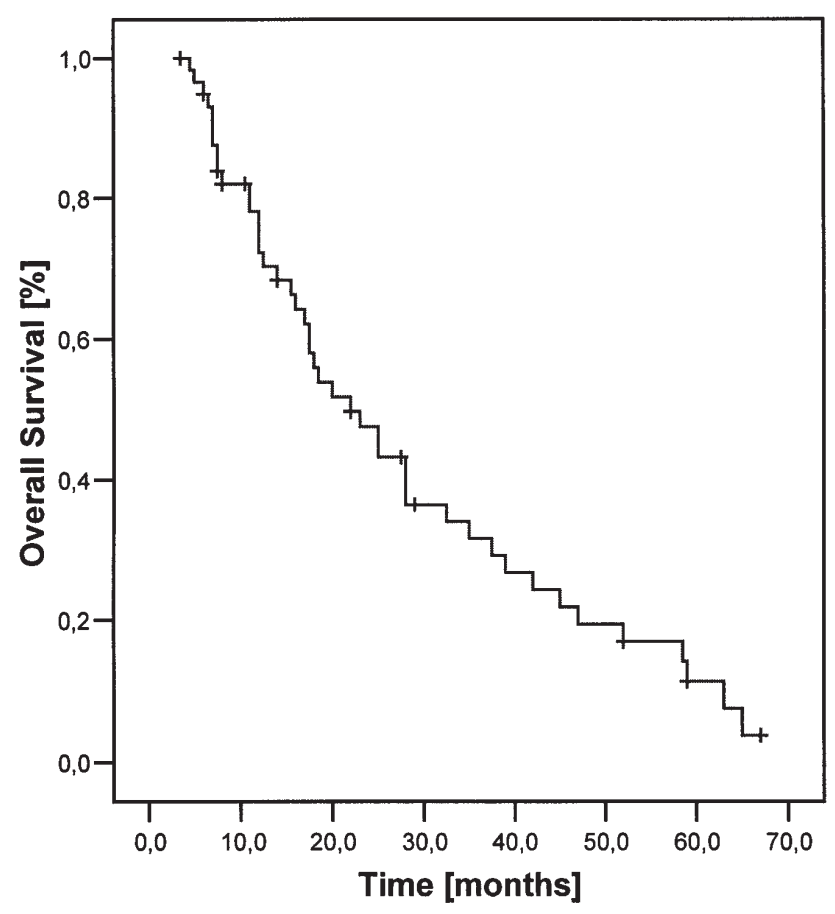

Figure 1. Overall survival for the entire cohort of patients $(n=59)$.

25 patients $(42 \%)$ had an ECOG performance score of 1, and 10 patients (17\%) had an ECOG performance score of 2. Therefore, the large majority of dose modifications in this clinical trial were on the basis of a bad performance score and parallel diseases such as renal insufficiency, coronary heart disease, bronchial asthma, and other common diseases of older patients. Fifty-five patients $(93 \%)$ received monotherapy with gemcitabine after the three-drug regimen. The median number of treatment courses received in the monotherapy with gemcitabine was two (range, 0-33 courses).

Treatment efficacy. Forty-eight out of 59 patients (81\%) had major responses to treatment. The median survival of all patients was 22 months (Fig. 1), and the actuarial 1-year and 2-year survival rates were $68 \%$ (19 out of 59 patients died) and $39 \%$ (36 out of 59 patients died), respectively. Thirtythree patients $(56 \%)$ achieved complete responses. After a median follow-up of 17.5 months, 29 patients remained alive and 25 were free of disease progression. The median progression-free survival for the entire group was 10 months (Fig. 2); for patients with objective responses, the median progression-free survival was 14 months (Fig. 3). The median survival time was very different according to the ECOG performance status (Fig. 4): The median survival time for patients with an ECOG status of 0 was 37.5 months, for patients with a status of 1,17 months, and for patients with a status of 2, 12 months.

Toxicity. Neutropenia was the most common grade 3 or 4 toxicity produced by this treatment regimen (Table III). Twenty-three patients (34\%) experienced grade 3-4 neutropenia, and 13 patients required hospitalization for the treatment of neutropenia and fever. No case of severe thrombocytopenia and no bleeding episodes were reported. 


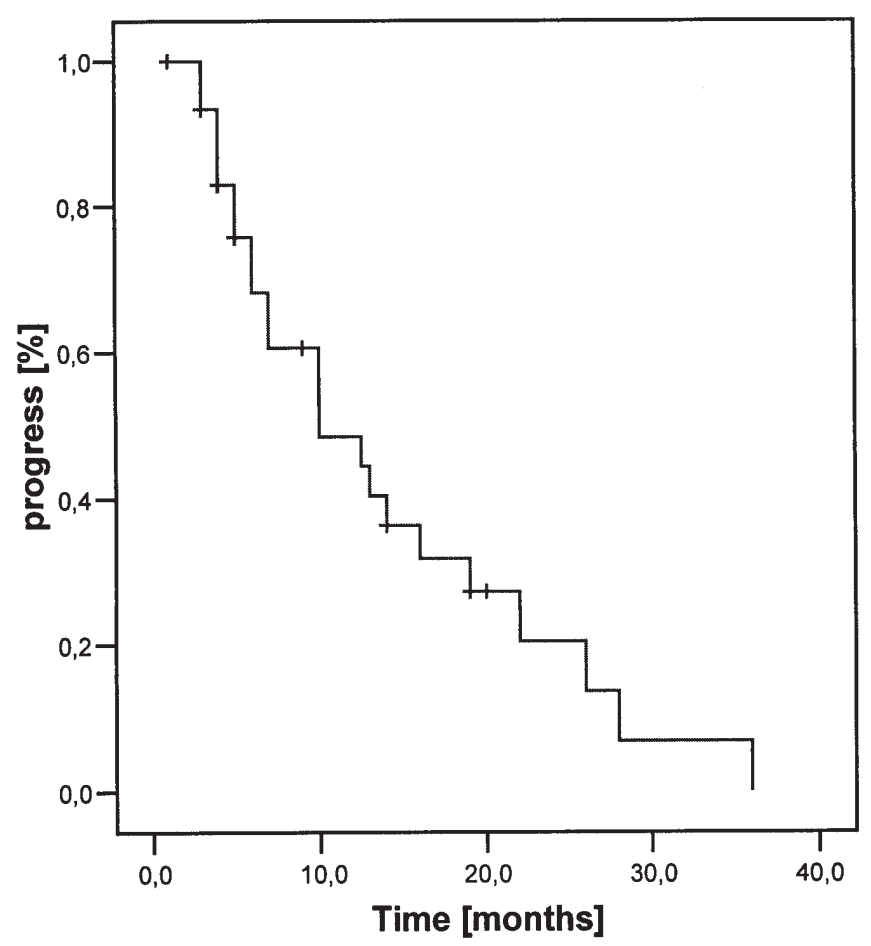

Figure 2. Time-to-progress for all the patients.

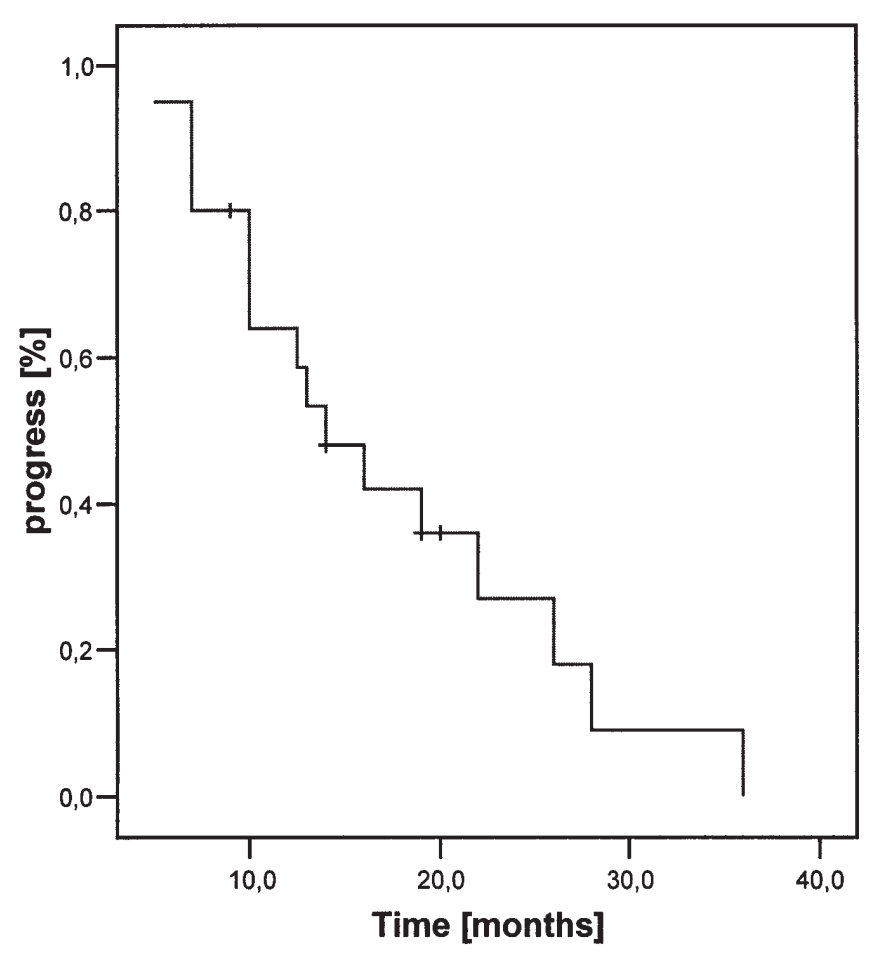

Figure 3. Time-to-progress for patients with objective response.

Severe nonhematological toxicity was uncommon with this treatment regimen. Twenty patients (34\%) experienced treatment-related fatigue; emesis was reported in 14 cases $(24 \%)$. More severe was the treatment-related nausea in 22 cases $(37 \%)$.

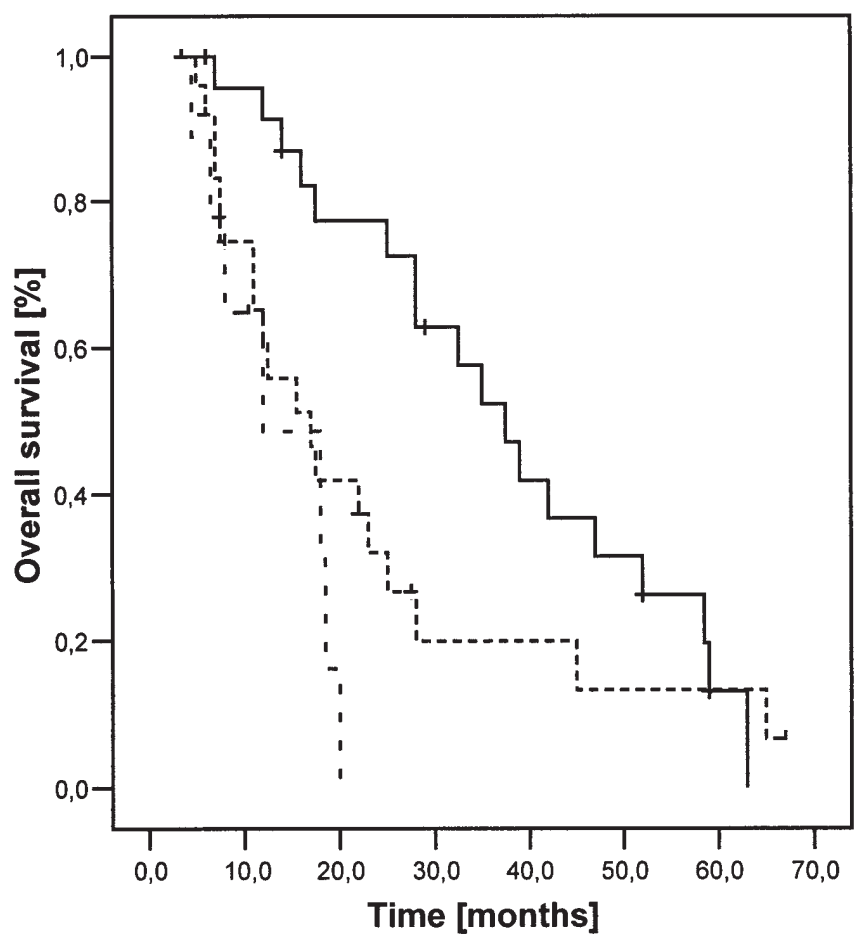

Figure 4. Overall survival for the entire cohort of patients $(n=59)$ according to the ECOG performance score $(0,-, 1,-\cdots,-, 2, \ldots-\ldots)$.

Table III. Treatment-related toxicity $(\mathrm{n}=59$ patients $/ 284$ courses).

Toxicity No. of patients $(\%)$

Hematological

Neutropenia (grade 3)

Neutropenia (grade 4)

Anemia

Thrombocytopenia

Nonhematological

Nausea

Emesis

\section{Discussion}

This three-drug regimen with a combination of gemcitabine, paclitaxel, and cisplatin was well tolerated and highly effective as a first-line treatment for advanced urothelial carcinoma, as demonstrated by the response rate, the median time to progression and median survival.

Cisplatin-based chemotherapy represents the most effective treatment for advanced urothelial cancer. Nevertheless, the majority of these patients are elderly, have impaired renal function, or have a poor performance status that make them unfit for such treatment. We therefore used the effective three-drug regimen of gemcitabine, paclitaxel and cisplatin with dose modifications for the unfit patients. 
Table IV. Main patient characteristics and prognostic factors of the two gemcitabine containing triplet studies and our results.

\begin{tabular}{lcccc}
\hline & $\begin{array}{c}\text { Hussain } \text { et al }(41) \\
\text { P carbo G study } \\
(\mathrm{n}=49)\end{array}$ & $\begin{array}{c}\text { Bellmunt } \text { et al (36) } \\
\text { PCG study } \\
(\mathrm{n}=61)\end{array}$ & $\begin{array}{c}\text { Lorusso } \text { et al }(42) \\
\text { PCG } \\
(\mathrm{n}=42)\end{array}$ & $\begin{array}{c}\text { Our results } \\
\text { PCG } \\
(\mathrm{n}=59)\end{array}$ \\
\hline Median age & 63 & 66 & 69 & 70 \\
ECOG status 0/1/2 & $24 / 20 / 5$ & $21 / 34 / 6$ & $18 / 16 / 8$ & $24 / 26 / 9$ \\
Metastatic \% & 80 & 82 & 76 & 59 \\
Visceral metastases \% & 49 & 36 & 55 & 15 \\
Overall response (OR) \% & 68 & 78 & 43 & 81 \\
Complete response (CR) \% & 32 & 28 & 12 & 56 \\
Median survival & 14.3 & 24 & 15.3 & 22 \\
\hline
\end{tabular}

In the three reported gemcitabine triplets $(36,41,42)$ responses were seen at all sites, including visceral metastases, and the median survival in the cohort of patients with visceral disease was still 14.3, 11.4, and 15.3 months. Table IV shows patient characteristics and the main prognostic factor distributions for these studies in comparison with our results. The overall response rate in the patients with visceral metastases was $77.6 \%$ for the cisplatin-based regimen of Bellmunt et al (36), and 68\% for the carboplatin-based therapy of Hussain et al (41). Lorusso et al found an overall response rate of only $43 \%$ (42). The historical data from the MVAC series showed response rates as low as $20 \%$ in patients with visceral disease $(10,12,43)$. Also the median survival time for patients who received the PCG-triplet regimen was with 14.3 months compared to that observed with the MVAC series. In our study $81 \%$ had major responses to treatment. The median survival of all the patients was very high with 22 months and very close to the median survival time of 24 months from Bellmunt et al (36). Thirtythree patients $(56 \%)$ achieved complete responses. The median progression-free survival for the entire group was 10 months; for patients with objective responses, the median progressionfree survival was 14 months. As it is already known that the ECOG performance status is a predictive factor for survival and response (44) we found a different median survival time according to this factor: The median survival time for patients with an ECOG status of 0,1, and 2 was 37.5, 17 and 12 months, respectively. These results are in general agreement with the results of Bellmunt et al (36). The lower percentage of patients with metastasis $(59 \%)$, and of patients with visceral metastasis $(15 \%)$ could be the reason for the better response to therapy in comparison to the results of Bellmunt et al, and Hussain et al $(36,41,45)$. It is also possible however, that the supportive therapy has improved with the years. Androulakis et al treated a group of 26 patients with the three-drug regimen (46). They had $16.7 \%$ complete response, and $33.3 \%$ partial response; because of the short follow-up they could not give a median survival time.

New promising regimes include combinations of chemotherapeutical drugs. During investigations of new drugs and drug combinations in advanced urothelial cancer, it should be emphasized that patients with good prognostic features have a $15-20 \%$ possibility of long-term survival and potential cure by use of effective chemotherapy $(44,47)$. It is extremely important that these patients are offered effective and not suboptimal chemotherapy (4).

Our treatment was designed on the basis that paired combinations of paclitaxel, gemcitabine and cisplatin, which represent three of the most active single agents in advanced urothelial cancer, and these combinations have been shown to achieve higher response rates than any of the three agents alone. Combination chemotherapy offers the potential to optimise response rates and survival by using agents with complementary mechanisms of action (48).

Besides the development of new chemotherapeutic drug regimes, another approach is the integration of biologically targeted agents into combined modality treatment. Similarly research within molecular biology in bladder cancer may improve our possibilities in selecting patients for different treatment regimes based on new and more specific markers than the ones we have today (49-51).

The addition of paclitaxel to the gemcitabine/cisplatin regimen was found to increase toxicity without any evidence of improved efficacy. Continued clinical analysis of current regimens as well as the development of novel combinations, will be necessary for the continued improvement in the treatment of patients with advanced urothelial carcinoma.

In conclusion, the partial response rate was $81 \%$, and the complete response rate was $56 \%$. The median actuarial survival was 22 months, and the actuarial 1-year and 2-year survival rates were $68 \%$ and $39 \%$, respectively. After a median follow-up of 17.5 months, 29 patients remained alive and 25 were free of disease progression. The median progression-free survival for the entire group was 10 months. The combination of gemcitabine, paclitaxel, and cisplatin is a highly effective and tolerable regimen for patients with advanced urothelial carcinoma. This treatment should be considered as a suitable option deserving further prospective evaluation. The ECOG performance status is an important predictive factor for survival.

\section{Acknowledgements}

We thank all the involved patients for their participation, and the staff of the Department of Urology and the Institute of 
Pathology at the Helios Hospital in Bad Saarow for their excellent assistance.

\section{References}

1. Aben KK, Witjes JA, Schoenberg MP, et al: Familial aggregation of urothelial cell carcinoma. Int J Cancer 41: 89-106, 2002.

2. Sternberg CN, Marini L and Calabro F: Systemic chemotherapy of bladder cancer. In: Bladder Cancer: Biology and Management. Skinner DG and Syrigos KN (eds). Oxford University Press, New York, pp299-315, 1999.

3. De Braud F, Maffezzini M, Vitale V, et al: Bladder Cancer. Crit Rev Oncol Hematol 41: 89-106, 2002.

4. Von der Maase H: Current and future perspectives in advanced bladder cancer: is there a new standard? Semin Oncol 29 (suppl 3): 3-14, 2002

5. Sternberg CN: Gemcitabine in bladder cancer. Semin Oncol 27 (suppl 2): 31-9, 2000.

6. Loehrer P, Einhorn LH, Elson PJ, et al: A randomized comparison of cisplatin alone or in combination with methotrexate, vinblastine, and doxorubicin in patients with metastatic urothelium carcinoma of the bladder: a cooperative group study. J Clin Oncol 10: 1066-1073, 1992.

7. Soloway MS, Einstein A, Corder MP, et al: A comparison of cisplatin and the combination of cisplatin and cyclophosphamide in advanced urothelial cancer. A National Bladder Cancer Collaborative Group A Study. Cancer 52: 767-772, 1983.

8. Scher HI, Shipley WU and Herr HW: Cancer of the Bladder. In: Cancer principles and practice of oncology. DeVita VT Jr, Hellman S and Rosenberg SA (eds). 5th edition. LippincottRaven, Philadelphia, pp1300-1322, 1997.

9. Yagoda A: Chemotherapy of urothelial tract tumors. Cancer 60: 574-585, 1987

10. Sternberg CN, Yagoda A, Scher HI, et al: Preliminary results of M-VAC (methotrexate, vinblastine, doxorubicin and cisplatin) for transitional cell carcinoma of the urothelium. J Urol 133: 403-407, 1985.

11. Sternberg CN, Yagoda A, Scher HI, et al: Methotrexate, vinblastine, doxorubicin, and cisplatin for advanced transitional cell carcinoma of the urothelium: efficacy and patterns of response and relapse. Cancer 64: 2448-2458, 1989.

12. Logothetis CJ, Dexeus FH, Finn L, et al: A prospective randomized trial comparing $\mathrm{M}-\mathrm{VAC}$ and CISCA chemotherapy for patients with metastatic urothelial tumors. J Clin Oncol 8: 1050-1055, 1990.

13. Von der Maase H, Hansen SW, Roberts JT, et al: Gemcitabine and cisplatin versus methotrexate, vinblastine, doxorubicin, and cisplatin in advanced or metastatic bladder cancer: results of a large, randomized, multinational, multicenter, Phase III study. J Clin Oncol 18: 3068-3077, 2000.

14. McCaffrey JA, Hilton S, Mazumdar M, et al: Phase II trial of docetaxel in patients with advanced or metastatic transitional cell carcinoma. J Clin Oncol 15: 1853-1857, 1997.

15. De Witt R, Kruit WH, Stoter G, et al: Docetaxel (Taxotere): an active agent in metastatic urothelial cancer: results of a phase II study in non-chemotherapy-pretreated patients. Br J Cancer 78: 1342-1345, 1998 .

16. Roth B, Dreicer R, Einhorn LH, et al: Significant activity of paclitaxel in advanced transitional-cell carcinoma of the urothelium: a phase II trial of the ECOG. J Clin Oncol 12: 2264-2270, 1994

17. Papamichael D, Gallagher CJ, Oliver RTD, et al: Phase II study of paclitaxel in pretreated patients with locally advanced/ metastatic cancer of the bladder and ureter. Br J Cancer 75: 606607,1997

18. Broome CM, Hussain M, Gutheil J, et al: Phase II trial of weekly paclitaxel in patients with previously treated advanced urothelial cancer. Proc Am Soc Clin Oncol 19: 351, 2000

19. Pollera CF, Ceribelli A, Crecco M, et al: Weekly gemcitabine in advanced bladder cancer. A preliminary report from a phase I study. Ann Oncol 5: 182-184, 1994.

20. Stadler WM, Kuzel T, Roth B, et al: Phase II study of singleagent gemcitabine in previously untreated patients with metastatic urothelial cancer. J Clin Oncol 15: 3394-3398, 1997.
21. Moore MJ, Tannock IF, Ernst DS, et al: Gemcitabine: a promising new agent in the treatment of advanced urothelial cancer. J Clin Oncol 15: 3441-3445, 1997.

22. Lorusso V, Pollera CF, Antimi M, et al: A Phase II study of gemcitabine in patients with transitional cell carcinoma of the urinary tract previously treated with platinum. Italian Cooperative Group on Bladder Cancer. Eur J Cancer 34: 1208$1212,1998$.

23. Boven E, Schipper AH, Erkeleus CAM, et al: The influence of the schedule and the dose of gemcitabine on the anti-tumor efficacy in experimental human cancer. Br J Cancer 68: 52-56, 1993.

24. Gatzemeier U, Shepherd FA, Le Chevallier T, et al: Activity of gemcitabine in patients with non-small cell lung cancer: a multi-centre extended phase II study. Eur J Cancer 32: 243248, 1996.

25. Moore M: Activity of gemcitabine in patients with advanced pancreatic carcinoma (Review). Cancer 78 (suppl 3): 633-638, 1996.

26. Shapiro JD, Milward MJ, Rischin D, et al: Activity of gemcitabine in patients with advanced ovarian cancer: responses seen following platinum and paclitaxel. Gynecol Oncol 63: 89-93, 1996.

27. Peters GJ, Bergman AM, Ruiz van Haperen VW, et al: Interaction between cisplatin and gemcitabine in vitro and in vivo. Semin Oncol 22 (suppl 11): 72-79, 1995.

28. Fuchs DA and Johnson RK: Cytologic evidence that Taxol, antineoplastic agent from Taxus Brevifolia, acts as a mitotic spindle poison. Cancer Treat Rep 62: 1219-1222, 1978.

29. Rangel C, Niell H, Miller A, et al: Taxol and taxotere in bladder cancer: In vitro acticity and urine stability. Cancer Chemother Pharmacol 33: 460-464, 1994.

30. Murphy BA, Johnson DR, Smith J, et al: Phase II trial of paclitaxel and cisplatin for metastatic or locally unresectable urothelial cancer. Proc Am Soc Clin Oncol 15: 245, 1996.

31. Burch PA, Richardson RL, Cha SS, et al: Phase II trial of combination paclitaxel and cisplatin in advanced urothelial carcinoma. Proc Am Soc Clin Oncol 18: 329, 1999.

32. Dreicer R, Manola J, Roth B, et al: Phase II study of cisplatin and paclitaxel in advanced carcinoma of the urothelium: an Eastern Cooperative Oncology Group (ECOG) study. J Clin Oncol 18: 1058-1061, 2000.

33. Dimopoulos MA, Bakoyannis C, Georgoulias V, et al: Docetaxel and cisplatin combination chemotherapy in advanced carcinoma of the urothelium: a multicenter phase II study of the Hellenic Cooperative Oncology Group. Ann Oncol 10: 1385-1388, 1999.

34. Sengeløv L, Kamby C, Lund B, et al: Docetaxel and cisplatin in metastatic urothelial cancer: a phase II study. J Clin Oncol 16: 3392-3397, 1998.

35. Garcia del Muro, Marcuello E, Guma R, et al: Phase II trial multicentre study of docetaxel plus cisplatin in patients with advanced urothelial cancer. Br J Cancer 86: 326-330, 2002.

36. Bellmunt J, Guillem V, Paz-Ares L, et al: Phase I/II study of paclitaxel, cisplatin, and gemcitabine in advanced transitionalcell carcinoma of the urothelium. J Clin Oncol 18: 3247-3255, 2000.

37. Bellmunt J, Guillem V, Paz-Ares L, et al: Pretreatment prognostic factors for survival in patients with advanced urothelial tumors Treated in a Phase I/II trial with paclitaxel, cisplatin, and gemcitabine. Cancer 95: 751-757, 2002.

38. Oken MM, Creech RH, Tormey DC, et al: Toxicity and response criteria of the Eastern Cooperative Oncology Group. Am J Clin Oncol 5: 649-655, 1982.

39. Hainsworth JD, Meluch AA, Litchy S, et al: Paclitaxel, carboplatin, and gemcitabine in the treatment of patients with advanced transitional cell carcinoma of the urothelium. Cancer 103: 2298-2303, 2005.

40. Kaplan EL and Meier P: Nonparametric estimates from incomplete observations. J Am Stat Assoc 53: 457-481, 1958.

41. Hussain M, Vaishampayan U, Du W, et al: Combination carboplatin, paclitaxel and gemcitabine. Is an active treatment for advanced urothelial carcinoma. J Clin Oncol 19: 2527-2533, 2001.

42. Lorusso V, Crucitta E, Silvestris N, et al: Randomized, openlabel, phase II trial of paclitaxel, gemcitabine and cisplatin versus gemcitabine and cisplatin as first-line chemotherapy in advanced transitional cell carcinoma of the urothelium. Oncol Rep 13: 283-287, 2005. 
43. De Wit R and Bellmunt J: Overview of gemcitabine triplets in metastatic bladder cancer. Crit Rev Oncol Hematol 45: 191-197, 2003.

44. Bajorin DF, Dodd PM, Mazumdar M, et al: Long-term survival in metastatic transitional-cell carcinoma and prognostic factors predicting outcome of therapy. J Clin Oncol 17: 3173-3181, 1999.

45. Bellmunt J, Guillem V, Paz-Ares L, et al: Gemcitabine/ paclitaxel-based three-drug regimens in advanced urothelial cancer. Eur J Cancer 36 (suppl 2): 17-25, 2000.

46. Androulakis N, Boukovinas I, Bozionelou V, et al: Sequential administration of cisplatin (c), gemcitabine (g) and docetaxel (d), as first-line treatment in patients with advanced transitional cell carcinoma (TCC) of the urothelial tract: A multicenter phase II study. J Clin Oncol 24: 14574, 2006.
47. Stadler WM, Hayden A, von der Maase H, et al: Long-term survival in Phase II trials of gemcitabine plus cisplatin for advanced transitional cell cancer. Urol Oncol 7: 153-157, 2002.

48. Pectasides D, Glotsos J, Bountouroglou N, et al: Weekly chemotherapy with docetaxel, gemcitabine and cisplatin in advanced transitional cell urothelial cancer: a phase II trial. Ann Oncol 13: 243-250, 2002.

49. Bellmunt J, De Witt R, Albiol S, et al: New drugs and new approaches in metastatic bladder cancer. Crit Rev Oncol Hematol 47: 195-206, 2003.

50. Von der Maase H: Gemcitabine in transitional cell carcinoma of the urothelium. Expert Rev Anticancer Ther 3: 11-19, 2003.

51. Sanchez-Carbayo M: Recent advances in bladder cancer diagnostics. Clin Biochem 37: 562-571, 2004 